\title{
Dy-Li (Dysprosium-Lithium)
}

\author{
H. Okamoto
}

The Dy-Li phase diagram was unknown in [Massalski2].

Figure 1 shows the Dy-Li phase diagram constructed based on a schematic phase diagram and a table of invariant reaction temperatures and compositions given in [1998Gan].

Table 1 shows Dy-Li crystal structure data.

\section{Reference}

1998Gan: N.N. Ganiev, Kh.M. Nazarov, and M.D. Badalov, Interaction of Lithium with Rare-earth Metals, Izv. Ross. Akad. Nauk, Metally, 1998, (6), p 109-112, in Russian; TR: Russ. Metall., 1998, (6), p 132-136

Table 1 Dy-Li crystal structure data

\begin{tabular}{lccccc}
\hline Phase & Composition, at.\% Li & Pearson symbol & Space group & Strukturbericht designation & Prototype \\
\hline$(\beta \mathrm{Dy})$ & 0 & $c I 2$ & $\operatorname{Im} \overline{3} m$ & $A 2$ & $\mathrm{~W}$ \\
$(\alpha \mathrm{Dy})$ & 0 & $h P 2$ & $P 6_{3} / m m c$ & $A 3$ & $\mathrm{Mg}$ \\
$(\beta \mathrm{Li})$ & 100 & $\operatorname{Im} \overline{3} m$ & $A 2$ & $\mathrm{~W}$ \\
\hline
\end{tabular}

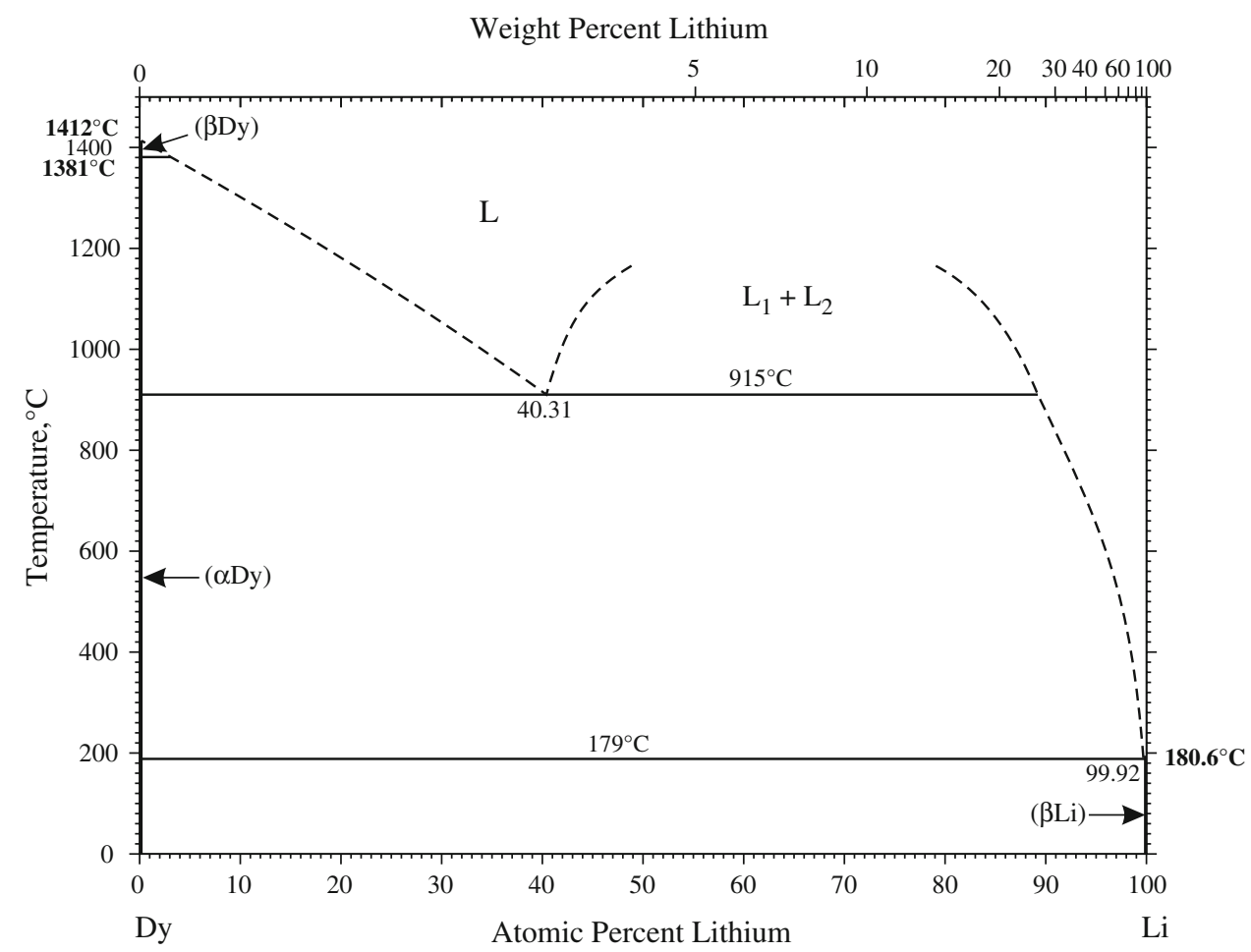

Fig. 1 Dy-Li phase diagram 